Please do not remove this page

RMIT

UNIVERSITY

\title{
The role of negative urgency impulsivity and financial management practices in compulsive buying
}

Alemis, Melissa; Yap, Keong Ann

https://researchrepository.rmit.edu.au/esploro/outputs/9921859975601341/filesAndLinks?institution=61RMIT_INST\&index=null

Alemis, M., \& Yap, K. A. (2013). The role of negative urgency impulsivity and financial management practices in compulsive buying. Australian Journal of Psychology, 65(4), 224-231.

https://doi.org/10.1111/ajpy.12025

Document Version: Accepted Manuscript

Published Version: https://doi.org/10.1111/ajpy.12025

Repository homepage: https://researchrepository.rmit.edu.au

(c) 2013 The Australian Psychological Society

Downloaded On 2023/04/26 21:01:19 +1000 
Thank you for downloading this document from the RMIT Research Repository.

The RMIT Research Repository is an open access database showcasing the research outputs of RMIT University researchers.

RMIT Research Repository: http://researchbank.rmit.edu.au/

\section{Citation:}

Alemis, M and Yap, K 2013, 'The role of negative urgency impulsivity and financial management practices in compulsive buying', Australian Journal of Psychology, vol. 65, no. 4, pp. 224-231.

See this record in the RMIT Research Repository at: https://researchbank.rmit.edu.au/view/rmit:22707

Version: Accepted Manuscript

Copyright Statement: ㄷ 2013 The Australian Psychological Society

Link to Published Version:

http://dx.doi.org/10.1111/ajpy.12025 
This is an electronic version of an article published in the Australian Journal of Psychology, December 2013: Alemis, M. C. and Yap, K. (2013), 'The role of negative urgency impulsivity and financial management practices in compulsive buying', Australian Journal of Psychology, vol. 65, no. 4, pp. 224-231. doi:

10.1111/ajpy.12025 
This is the post print version of the following article: Alemis, M. \& Yap, K. (2013). The role of negative urgency impulsivity and financial management practices in compulsive buying. Australian Journal of Psychology, 65, 224-231. DOI: 10.1111/ajpy.12025 which has been published in final form at http://onlinelibrary.wiley.com/doi/10.1111/ajpy.12025/abstract 
Predictors of Compulsive Buying: Psychological Distress, Impulsivity, and Financial Management Practices

Melissa C. Alemis and Keong Yap

RMIT University

Author Note

Melissa C. Alemis, Discipline of Psychology, School of Health Sciences, RMIT University; Keong Yap, Discipline of Psychology, School of Health Sciences, RMIT University.

The authors would like to thank Ms Kate Gray for her assistance in data collection.

Correspondence concerning this article should be addressed to Keong Yap, School of Health Sciences, RMIT University, PO Box 71, Bundoora, Victoria 3083, Australia. Tel (+613) 9925 6692, Fax (+613) 99257 303, email: keong.yap@,rmit.edu.au.

Keywords: Compulsive buying; financial management practices; impulsivity 


\begin{abstract}
Previous research has shown that negative urgency impulsivity is associated with compulsive buying even after controlling for depression. The aim of the present study was to replicate this finding, and to examine if financial management practices mediated this relationship. A community sample of 162 participants (34 male and 128 female), aged between 18 and 82 years, completed online self-report questionnaire measures. As expected, results revealed (1) significant positive associations between compulsive buying and both negative urgency impulsivity (NUI) and psychological distress; and (2) a significant negative association between compulsive buying and financial management practices. We also found that after controlling for psychological distress (3) NUI was still significantly correlated with compulsive buying, and (4) financial management practices partially mediated the relationship between NUI and financial management practices. Our findings are consistent with an extension of the theory that compulsive buying is motivated by relieving negative mood states (Faber \& Christenson, 1996); positing both negative affect-driven impulsivity and psychological distress as important factors in understanding compulsive buying. These findings also support current cognitivebehavioural interventions for the treatment of compulsive buying that target psychological distress, negative urgency impulsivity, and financial management practices.
\end{abstract}


The role of Negative Urgency Impulsivity and

Financial Management Practices in Compulsive Buying

Buying is a normal part of life and many individuals often purchase items that they do not need or buy things impulsively and excessively. However, for some individuals, excessive impulse buying can become a severe compulsive buying problem with devastating financial and interpersonal consequences (DeSarbo \& Edwards, 1996). Such compulsive buying has been defined as (a) a recurrent preoccupation with buying and/or irresistible or disturbing urges to buy; (b) repetitive buying experienced as uncontrollable; and (c) causing significant psychological, social and/or financial harm (American Psychiatric Association, 2000; Dittmar, 2004; McElroy, Keck, Pope, Smith, \& Strakowski, 1994) and is estimated to affect $5.8 \%$ of the population (Koran, Faber, Aboujaoude, Large, \& Serpe, 2006). Despite the magnitude of this issue, discrepancy remains between compulsive buying theories that largely focus on the role of negative mood regulation (e.g., Faber \& Christenson, 1996) and recent research supporting the fundamental influence of impulsive personality on compulsive buying (Billieux, Rochat, Rebetez, \& Van Der Linden, 2008). Moreover, the influence of financial management practices on impulsivity in the context of compulsive buying has not been accounted for in both theory and research. The current study aimed to find further evidence of the relationship between impulsivity and compulsive buying tendencies and to examine the potential mediating impact of financial management practices on this relationship.

\section{Compulsive Buying and Negative Mood Regulation}

Established theories underscore the importance of negative mood regulation in explaining compulsive buying (Dittmar, 2005; Faber, 2004; Faber \& Christenson, 1996; Faber \& Vohs, 
2004). Notably, Faber and Christenson (1996) proposed that compulsive buying is motivated by relieving negative mood states. This theory has been consistently supported by empirical evidence. For instance, Faber and Christenson (1996) compared the self-reported mood states of 24 compulsive buyers with a matched group of non-compulsive buyer controls and found that compulsive buyers recalled more frequent negative mood states prior to shopping and greater mood change immediately following buying. A number of studies have reported similar results (Christenson, Faber, de Zwaan, \& Raymond, 1994; Elliot, 1994; Miltenberger et al., 2003; Mueller et al., 2012). Many authors concur with the mood regulation explanation. Miltenberger and colleagues (2003), for example, suggested that compulsive buying episodes facilitated negative emotion improvement. This view is consistent with evidence that recognised drugs used for the treatment of mood disorders (i.e., antidepressants and mood stabilisers) were also effective in reducing or preventing compulsive buying urges and behaviour (Black, Monahan, \& Gabel, 1997; Koran et al., 2002; McElroy et al., 1994).

Conversely, recent empirical evidence has challenged the idea that compulsive buying is driven by alleviating negative affect. Williams (2012a) randomly allocated participants to either negative or positive mood induction procedures. Interestingly, regardless of the mood induction condition, compulsive buyers reported greater urges to buy, purchased more items, and spent more money than a control group. Furthermore, they were also significantly faster at making purchasing decisions than a pathological gambling group. In another paper using the same sample, Williams (2012b) found that the compulsive buying group was just as impulsive as the pathological gambling group (as measured by self-report and behavioural responses) and significantly more impulsive than a healthy control group. These results suggested that impulsivity rather than mood regulation was the key causal factor in compulsive buying. 


\section{The Role of Negative Urgency Impulsivity}

Consistent with Williams' (2012a \& b) findings, recent studies have shown that compulsive buying was associated with measures of impulsivity and, in particular, negative urgency impulsivity. Negative urgency impulsivity is defined as a disposition to experience inhibition difficulties and react to adverse negative affect despite future negative consequences (Cyders \& Smith, 2008). Billieux and colleagues (2008) evaluated 150 participants (mainly students) on self-report measures of compulsive buying, trait-level anxiety, depression, and impulsivity. They found that compulsive buying was associated with negative affect and different forms of impulsivity (lack of premeditation, lack of perseverance, and urgency). However, only negative urgency impulsivity significantly predicted compulsive buying after controlling for depression. Other studies have corroborated a significant positive relationship between negative urgency impulsivity and compulsive buying (Billieux, Gay, Rochat, \& Van der Linden, 2010; Williams \& Grisham, 2011). In interpreting results, Billieux and colleagues (2008) maintained the idea of negative mood regulation but favoured negative affect-driven impulsivity as the principal motivator of compulsive buying. This explanation is consistent with Cyders and Smith's (2008) view that individuals with greater dispositional negative urgency impulsivity are more prone to managing their negative affective states through engaging in maladaptive behaviours. In other words, both impulsivity and negative mood regulation are important components of compulsive buying. Such a view is consistent with Kellett and Bolton's (2009) cognitive-behavioural model of compulsive buying, which suggests that impulsivity is an antecedent factor whereas negative mood regulation is a factor that has impact during the act of buying.

\section{The role of Financial Management Practices}


Recent empirical evidence has not only supported negative urgency impulsivity as a predictor of compulsive buying (Billieux et al., 2008) but also financial management practices (Lo \& Nigel, 2011; Pham, Yap, \& Dowling, 2012). Financial management practices provide a vigilant approach for handling household assets and liabilities to improve financial status, which integrates cash management, credit management, capital accumulation, risk management, retirement and estate planning, and general management (Parrotta \& Johnson, 1998). Pham and colleagues (2012) evaluated 118 participants on self-report measures of compulsive buying, financial management practices, financial attitudes, and materialistic values. They found that financial management practices significantly predicted compulsive buying and astute financial management lessened the influence of materialistic values on compulsive buying. While it is currently not known whether general financial management practices have any influence on the relationship between negative urgency impulsivity and compulsive buying, there is evidence that greater impulsivity is associated with poorer financial management practices (Ottaviani \& Vandone, 2011). It follows that one of the pathways that impulsivity might impact on compulsive buying is through its association with financial management practices (see Figure 1).

Insert Figure 1 here

\section{Rationale, Aims and Hypotheses}

Recent empirical evidence have shown a positive relationship between negative urgency impulsivity and compulsive buying (Billieux et al., 2010; Billieux et al., 2008; Williams \& Grisham, 2011). We suggest that this relationship might be partly due to an association between 
negative urgency impulsivity and poor financial management practices. It was hypothesised that: (1) compulsive buying would be positively correlated with negative urgency impulsivity and psychological distress; (2) compulsive buying would be negatively correlated with financial management practices. In addition, we hypothesised that after controlling for psychological distress, (3) negative urgency impulsivity would be significantly correlated with compulsive buying and (4) financial management practices would partially mediate the relationship between negative urgency impulsivity and compulsive buying.

\section{Method}

\section{Participants}

The current community sample consisted of voluntary participants recruited through word of mouth, circulating informational flyers at shopping centre entrances, online forums, and social networking sites. There were 177 participants (37 male and 140 female) who commenced the survey but only 162 participants ( 34 male and 128 female) completed the survey $(91.5 \%$ completion rate) and were included in the final sample. These participants' ages ranged from 18 to 82 years $(M=36.20$ years, $S D=12.77$ years $)$. Further details of the sample are reported in Table 1.

Insert Table 1 here

\section{Materials}


Participants were administered a set of questionnaires to assess demographics, compulsive buying, psychological distress, impulsivity traits, and financial management practices. Demographic information collected included gender, age, education level, employment and marital status, accommodation, credit card use, debt, and annual income. Measures are as follows.

Compulsive Buying Scale (CBS; Faber \& O'Guinn, 1992). The 7-item CBS instrument was used to measure the severity of compulsive buying in participants (e.g. 'bought myself something in order to make myself feel better'). The first item concerned extent of agreement (measured using a 5-point Likert scale: $1=$ 'strongly agree' to $5=$ 'strongly disagree') and the following six items related to frequency (measured using a 5-point Likert scale: $1=$ 'very often' to $5=$ 'never') of engaging in stated behaviours. Faber and O'Guinn's (1992) equation provided an index of compulsive buying severity; lower scores indicated greater compulsive buying but a score equal to or less than -1.34 suggested clinically significant compulsive buying. As a clinical screener, the CBS has shown good internal consistency reliability (Cronbach's alpha $\alpha=.95$ ) and reasonable criterion and construct validity (e.g. weighted scoring equation correctly classified approximately 88 per cent of participants) (Faber \& O'Guinn, 1992). Cronbach's alpha in the current sample was good $(\alpha=.79)$. There were 13 participants $(8 \%)$ in the final sample of $(n=$ 162), who received a CBS score of less than or equal to -1.34. As compulsive buying was examined on a continuum similar to some past studies (Joireman, Kees, \& Sprott, 2010; Mowen \& Spears, 1999; Rose, 2007), CBS scores were treated as a continuous rather than discrete variable.

The UPPS-P Impulsivity Scale (Lynam et al., 2006). This 59-item instrument is a revised version of the UPPS Impulsive Behavior scale (Whiteside \& Lynam, 2001), which has 
reclassified the original Urgency subscale as Negative Urgency and included a Positive Urgency subscale. The UPPS-P has five impulsivity trait subscales: (lack of) Premeditation, Negative Urgency, Sensation Seeking, (lack of) Perseverance, and Positive Urgency. Participants rated each item on a 4-point Likert scale ( $1=$ 'agree strongly' to $4=$ 'disagree strongly'). In the current study, only the Negative Urgency subscale data was analysed (12 items e.g. 'when I feel bad, I will often do things I later regret in order to make myself feel better now'). All items except one were reverse-scored. The means of item scores were calculated; greater mean scores reflected higher negative urgency impulsivity. The Urgency (now Negative Urgency) subscale was found to have good internal consistency $(\alpha=.86)$ and criterion/concurrent validity (i.e. correlated with all six dimensions of Neuroticism in McCrae and Costa's (1990) well-established NEO-PI-R) (Whiteside \& Lynam, 2001). Cronbach's alpha in the current sample was high ( $\alpha=$ $.89)$.

Financial Management Scale (FMS; Parrotta \& Johnson, 1998). The 35-item FMS was used to evaluate general financial management practices including cash management, credit management, retirement and estate planning, risk management, general management, and capital accumulation (e.g. 'I regularly set money aside for possible unexpected expenses'). Items were rated using a 5 -point Likert scale $(1=$ 'not typical' to $5=$ 'typical'). All item scores were added together allowing for eight reverse-scored items; higher scores indicated better financial management practices. The FMS was shown to have suitable construct validity and good internal consistency $(\alpha=.86)$ (Parrotta \& Johnson, 1998). Cronbach's alpha in the current sample was high $(\alpha=.93)$, which excluded question 3 ('sometimes I write bad cheques or ones with insufficient funds') due to zero variance. Accordingly, a revised 34-item FMS scale was used in present study data analyses. 
Depression Anxiety Stress Scale (DASS; Lovibond \& Lovibond, 1995). The 21-item DASS instrument was used to measure degree of distress using three subscales consisting of seven items each: depression (e.g., 'I felt that life was meaningless'), anxiety (e.g., 'I experienced trembling in my hands'), and stress (e.g., 'I found it hard to wind down') symptoms. Statement items were rated on a 4-point scale pertaining to the extent they applied over the last week; initially coded online from $1=$ 'did not apply to me at all' to $4=$ 'applied to me very much, or most of the time' but converted to a scale range from 0 to 3 prior to analyses. The item scores of each subscale were summed and multiplied by two; subscale scores were added to give the DASS Total score. The DASS Total scale was demonstrated to have good internal consistency $(\alpha=0.93)$ as well as criterion/concurrent validity (i.e. correlated with wellestablished measures of anxiety and depression) (Henry \& Crawford, 2005). Cronbach's alpha in the current sample was high $(\alpha=.94)$.

\section{Procedure}

Ethics approval was obtained from the RMIT College Human Ethics Advisory Network (CHEAN). Participants read the online Participant Information Statement and proceeded answering the web-based questionnaire (administered using www.surveymonkey.com) if they gave their consent and were aged 18 years or over. This survey required approximately 25 minutes to complete. Statistical analyses were conducted using SPSS (version 17.0).

\section{Design and Analysis}

The present study used a non-experimental design involving correlation and multiple regression analyses to determine relationships among variables and influence of predictors (DASS-Total distress, UPPS-P negative urgency, and FMS financial management) on the 
dependent variable (CBS compulsive buying). Subject to lower CBS scores representing greater compulsive buying, the operationalised forms of the first two hypotheses were inversed as follows: (1) CBS compulsive buying would be negatively correlated with UPPS-P negative urgency and DASS-Total distress; (2) CBS compulsive buying would be positively correlated with FMS financial management and (3) CBS compulsive buying would be negatively correlated with UPPS-P negative urgency even after controlling for DASS-Total distress. To test the hypothesised mediation model, a bootstrapping procedure (using biased controlled and accelerated confidence intervals from 5000 bootstrap samples) was conducted to estimate the indirect, direct and total effects of UPPS-P negative urgency on CBS compulsive buying through the mediating variable of FMS financial management practices (Preacher and Hayes, 2008). DASS-Total distress was included as a covariate in the model. The SPSS bootstrap macro (INDIRECT) was used to analyse the data (http://www.afhayes.com).

\section{Results}

\section{Preliminary analyses}

Tests of assumptions showed excessive skewness and kurtosis evident for both DASSTotal distress (positive skewness $=6.82$; positive kurtosis $=3.63$ ) and CBS compulsive buying (negative skewness $=-5.74 ;$ positive kurtosis $=5.40)$, according to $z$-score significance tests $(p<$ .01) (Field, 2008, 2009). This was consistent with the Kolmogorov-Smirnov test that showed both CBS compulsive buying and DASS-Total distress scores significantly deviated from normal distributions, $D(162)=0.10, p=.001$ and $D(162)=0.16, p<.001$, respectively. Furthermore, visual inspection of boxplots indicated one extreme univariate outlier for CBS compulsive buying across all variables. 


\section{Main analyses}

Due to violations to the normality assumption, the non-parametric Spearman's correlation coefficients were used to calculate all intercorrelations between CBS compulsive buying, DASSTotal distress, UPPS-P negative urgency, and FMS financial management. Means are shown in Table 2. The mean CBS compulsive buying score was well above the cut-off $(<-1.34)$ for clinically significant compulsive buying. There was a significant negative correlation found between DASS-Total distress and CBS compulsive buying, $r_{\mathrm{s}}(160)=-.30, p<.001$. There was a significant negative correlation demonstrated between UPPS-P negative urgency and CBS compulsive buying, $r_{\mathrm{s}}(160)-.31, p<.001$. FMS financial management was significantly positively correlated with CBS compulsive buying, $r_{\mathrm{s}}(160)=.40, p<.001$. These correlations were each deemed medium effect size (i.e. $\geq .30 \&<.50$ ) (Cohen, 1988, 1992). A partial Spearman's correlation was conducted to test hypothesis 3. Results showed that UPPS-P negative urgency remained significantly negatively correlated with CBS compulsive buying even after controlling for DASS-Total distress, $r_{s}(159)=-.21, p=.008$. Although not hypothesised, we also tested and found a significant correlation between DASS-Total distress and CBS compulsive buying after controlling for UPPS-P negative urgency, $r_{s}(159)=.194, p=.014$.

Insert Table 2 here

To test hypothesis 4 , a multiple regression and bootstrapping procedure was used to assess indirect effects of the proposed mediation model (Preacher \& Hayes, 2008). Results showed a significant effect of UPPS-P negative urgency on FMS financial management ( $a=$ - 
13.23, $p<.001$ ), a significant direct effect of FMS financial management on CBS compulsive buying $(b=.022, p<.001)$, a significant total effect of UPPS-P negative urgency on CBS compulsive buying $(c=-.831, p<.001)$, and a significant but reduced direct effect of UPPS-P negative urgency on CBS compulsive buying $\left(c^{\prime}=.547, p=.020\right)$. The partial effect of DASStotal distress was not significant $(p=.13)$. The indirect effect of UPPS-P negative urgency on CBS compulsive buying through the mediating variable of FMS financial management was significant, a X b $=-.28,95 \% \mathrm{CI}:[-.558,-.107]$.

\section{Discussion}

The results supported all hypotheses. Compulsive buying was positively correlated with both negative urgency impulsivity and psychological distress. Compulsive buying was negatively correlated with financial management practices. Moreover, negative urgency impulsivity was significantly correlated with compulsive buying even after controlling for psychological distress. Finally, the results showed that financial management practices partially mediated the relationship between negative urgency impulsivity and compulsive buying.

\section{Influence of Negative Urgency Impulsivity}

The significant positive association found between compulsive buying and negative urgency impulsivity in the current study was consistent with previous research (Billieux et al., 2010; Billieux et al., 2008; Williams \& Grisham, 2011). However, the present study revealed only a moderate correlation compared to strong correlations found in previous studies (Billieux et al., 2008; Williams \& Grisham, 2011). Moreover, confirmation of the third hypothesis verified previous empirical evidence that negative urgency impulsivity significantly predicted compulsive buying after controlling for negative affect (Billieux et al., 2008). However, the 
current study did not replicate the prior finding that negative urgency impulsivity rather than negative affect significantly predicted compulsive buying (Billieux et al., 2008). Instead, the present study found that both psychological distress and negative urgency impulsivity had independent effects on compulsive buying.

Independent effects of psychological distress and negative urgency impulsivity on compulsive buying found in this study were consistent with Kellett and Bolton's (2009) model that posits a critical role for both impulsivity and negative mood regulation factors. Consistent with Faber and Christenson (1996), compulsive buying is motivated by relieving psychological distress but should also be attributed to the impulse control difficulties that arise when individuals experience negative affect. Accordingly, present findings also challenged Billieux and colleagues (2008) argument that negative affect-driven impulsivity is the principal motivator of compulsive buying as opposed to negative affect regulation. Findings of the current study are consistent with Cyders and Smith's (2008) theory that individuals characterised by negative urgency impulsivity are more prone to regulate their negative affective states through engaging in maladaptive behaviours. However, in cases of compulsive buying, the present study highlights the importance of the desire to exclusively regulate negative affect irrespective of inhibition difficulties.

\section{Effect of Financial Management Practices}

The medium size negative correlation between financial management practices and compulsive buying found in this study was consistent with past research (Pham et al., 2012). The results also supported the proposed mediation model. Individuals with a more impulsive personality are also more likely to have problems with learning the habit of good financial 
management. The inability to save money and manage one's credit card debt then becomes a contributing factor to compulsive buying problems.

\section{Clinical Implications}

The current study examined compulsive buying behaviour existing along a continuum, similar to some past studies (Joireman, Kees, \& Sprott, 2010; Mowen \& Spears, 1999; Rose, 2007), using a community sample with mean scores almost two standard deviations above the clinical threshold of -1.34. Accordingly, the following suggested clinical avenues apply to the general public experiencing varying degrees of compulsive buying behaviour rather than exclusively for individuals experiencing clinically significant compulsive buying.

Based on current findings, we suggest that in addition to dealing with psychological distress and financial management practices, interventions for compulsive buying should also target negative affect-driven impulsivity. For example, an initial short-term approach for targeting negative urgency impulsivity might involve stimulus control and systematic exposure. Past research has shown stimulus control and in vivo exposure were effective for initially ceasing pathological gambling (Echeburua \& Fernandez-Montalvo, 2002). Along the same lines, an intervention for compulsive buying might involve: (a) identifying and initially avoiding triggers of negative emotion; and (b) gradually increasing exposure to these risks and extending time frames before responding to overcome impulsive behavioural reactions under psychological distress.

Alternatively, mindfulness-based interventions may also be suitable for long-term management of both negative urgency impulsivity and psychological distress that influence compulsive buying. Mindfulness-based interventions are concerned with increasing awareness 
and acceptance of triggers and internal reactions (e.g., negative affect) and promoting intentional rather than reactive behavioural responses (Bowen et al., 2009). Mindfulness-based approaches have been recommended for treatment of addictive behaviours, such as substance abuse (Bowen et al., 2009; Witkiewitz \& Bowen, 2010), and appear suitable for compulsive buying given the emphasis on acquiring acceptance of emotions and control over impulsive behaviour In the context of compulsive buying, mindfulness-based treatment may involve: (a) greater awareness of triggers for psychological distress and urges to engage in compulsive buying behaviour; (b) acceptance and tolerance of psychological distress rather than impulsively reacting and engaging in compulsive buying; and (c) developing alternative means of coping with psychological distress and non-reactive behaviour that supports one's long-term goals and attracts positive future consequences.

The mediational role and independent effect of financial management practices on compulsive buying supports financial management skills training in the prevention and treatment of compulsive buying. Past studies have successfully demonstrated the efficacy of group cognitive-behavioural interventions for compulsive buying which included instructions on cash management and discontinuing credit card use (Mitchell, Burgard, Faber, Crosby, \& de Zwaan, 2006; Mueller et al., 2008). Interestingly, Mueller and colleagues (2010) found that clients who were impulsive had poorer treatment response. Collectively, these treatment study findings support independently addressing both financial management practices and negative urgency impulsivity in cases of compulsive buying.

\section{Limitations}


Results of the current study should be interpreted in light of methodological issues. Firstly, as mentioned, caution should be taken when generalising our findings to individuals with clinical levels of compulsive buying. Nevertheless, it should be noted that our sample still comprised individuals with clinically significant compulsive buying problems; the prevalence of clinically significant compulsive buying in the sample $(8 \%)$ was higher than the estimated prevalence in the American population (5.8\%) (Koran et al., 2006). Furthermore, unlike previous studies (e.g., Billieux et al., 2008), the majority of participants were not university students and as such the sample was somewhat more representative of the general population.

Another limitation related to the small proportion of males compared to females in the current sample, indicating a gender bias that may have restricted generalisation of results to males. A recent epidemiological study estimated prevalence of compulsive buying as similar across males $(5.5 \%)$ and females $(6.0 \%)$ (Koran et al., 2006) and therefore, more males should have been included in the current sample to investigate compulsive buying in the general population.

The outcomes of this study were also limited by the exclusive use of self-report measures and thus relied on participant's ability to report accurately on their buying behaviours and financial management practices. Finally, this study was correlational and cross-sectional and therefore identified relationships did not imply causation. Future research using longitudinal designs may elucidate a perpetuating cycle of compulsive buying involving financial management practices, psychological distress, and negative urgency impulsivity.

\section{Conclusion}


The present study supported all the stated hypotheses. Our findings provide further evidence of the role of negative urgency impulsivity in compulsive buying. This supported an extension of the theory that compulsive buying is motivated by relieving negative mood states (Faber \& Christenson, 1996); positing negative affect-driven impulsivity and psychological distress both influencing compulsive buying. Furthermore, financial management practices were shown to have an independent effect on compulsive buying and partially mediated the relationship between negative urgency impulsivity and compulsive buying. The current findings suggest that interventions for compulsive buying should include methods for dealing with psychological distress and negative urgency impulsivity as well as improving financial management practices. 


\section{References}

American Psychiatric Association (2000). Diagnostic and Statistical Manual of Mental Disorders (Revised 4th ed.). Washington DC: American Psychiatric Association.

Barnett, V., \& Lewis, T. (1978). Outliers in statistical data. New York: John Wiley \& Sons Ltd.

Billieux, J., Gay, P., Rochat, L., \& Van der Linden, M. (2010). The role of urgency and its underlying psychological mechanisms in problematic behaviours. Behaviour Research and Therapy, 48(11), 1085-1096. doi: 10.1016/j.brat.2010.07.008

Billieux, J., Rochat, L., Rebetez, M. M., \& Van Der Linden, M. (2008). Are all facets of impulsivity related to self-reported compulsive buying behavior? Personality and Individual Differences, 44, 1432-1442. doi: 10.1016/j.paid.2007.12.011

Black, D. W., Monahan, P., \& Gabel, J. (1997). Fluvoxamine in the treatment of compulsive buying. Journal of Clinical Psychiatry, 58(4), 159-163.

Black, D. W., Monahan, P., Schlosser, S., \& Repertinger, S. (2001). Compulsive buying severity: an analysis of compulsive buying scale results in 44 subjects. Journal of Nervous Mental Disorders, 189, 123-126.

Bowen, S., Chawla, N., Collins, S. E., Witkiewitz, K., Hsu, S., Grow, J., . . Marlatt, A. (2009). Mindfulness-based relapse prevention for substance use disorders: A pilot efficacy trial. . Substance Abuse, 30, 295-305. doi: 10.1080/08897070903250084

Christenson, G. A., Faber, R. J., de Zwaan, M., \& Raymond, N. C. (1994). Compulsive buying: Descriptive statistics and psychiatric comorbidity. Journal of Clinical Psychiatry, 55, 511.

Cohen, J. (1988). Statistical power analysis for the behavioral sciences (2nd ed.). New York: Academic Press. 
Cohen, J. (1992). Quantitative methods in psychology: A power primer. Psychological Bulletin, 112(1), 155-159.

Cohen, J., \& Cohen, P. (1983). Applied multiple regression: Correlation analysis for the behavioural sciences (2nd ed.). Hilldale, NJ: Lawrence Erlbaum.

Cyders, M. A., \& Smith, G. T. (2008). Emotion-based dispositions to rash action: Positive and negative urgency. Psychological Bulletin, 134(6), 807-828. doi: 10.1037/a0013341

DeSarbo, W. S., \& Edwards, E. A. (1996). Typologies of compulsive buying behavior: A constrained clusterwise regression approach. Journal of Consumer Psychology, 5(3), 231262. doi: 10.1207/s15327663jcp0503_02

Dittmar, H. (2004). Understanding and diagnosing compulsive buying. In R. H. Coombs (Ed.), Handbook of Addictive Disorders: A practical guide to diagnosis and treatment (pp. 411451). New Jersey: John Wiley \& Sons.

Dittmar, H. (2005). A new look at "compulsive buying": Self-discrepancies and materialistic values as predictors of compulsive buying tendency. Journal of Social and Clinical Psychology, 24(6), 832-859.

Durbin, J., \& Watson, G. S. (1951). Testing for serial correlation in least squares regression, II. Biometrika, 30, 159-178.

Echeburua, E., \& Fernandez-Montalvo, J. (2002). Psychological treatment of slot machine pathological gambling: A case study. Clinical Case Studies, 1(3), 240-253.

Elliot, R. (1994). Addictive Consumptions: Function and fragmentation in post-modernity. Journal of Consumer Policy, 17(2), 159-179. doi: 10.1007/BF01016361 
Faber, R. J. (2004). Self-control and compulsive buying. In T. Kasser \& A. D. Kanner (Eds.), Psychology and consumer culture: The struggle for a good life in a materialistic world (pp. 169-187). Washington, DC, US: American Psychology Association.

Faber, R. J., \& Christenson, G. A. (1996). In the mood to buy: Differences in the mood states experienced by compulsive buyers and other consumers. Psychology and Marketing, 13(8), 803-819.

Faber, R. J., \& O'Guinn, T. C. (1992). A clincial screener for compulsive buying. Journal of Consumer Research, 19, 459-469.

Faber, R. J., \& Vohs, K. (2004). To buy or not to buy?: Self-control and self-regulatory failure in purchase behaviour. In R. F. Baumeister \& K. Vohs (Eds.), The Handbook of SelfRegulation (pp. 509-524). New York: Guilford.

Field, A. P. (2008). Exploring data. Research methods in psychology (pp. 1-14). London: Sage.

Field, A. P. (2009). Discovering statistics using SPSS: and sex and drugs and rock ' $n$ ' roll (3rd ed.). London: Sage.

Gray, J. A. (1981). A critique of Eysenck's theory of personality. In H. J. Eysenck (Ed.), A Model of Personality (pp. 246-276). New York: Springer.

Gray, J. A. (1987). Perspectives on anxiety and impulsivity: A commentary. Journal of Research in Personality, 21, 493-509.

Henry, J. D., \& Crawford, J. R. (2005). The short-form version of the Depression Anxiety Stress Scales (DASS-21): Construct validity and normative data in a large non-clinical sample. British Journal of Clinical Psychology, 44, 227-239. doi: 10.1348/014466505X29657 
Hui-Yi, L., \& Harvey, N. (2011). Shopping without pain: Compulsive buying and the effects of credit card availability in Europe and the Far East. Journal of Economic Psychology, 32, 79-92. doi: 10.1016/j.joep.2010.12.002

Joireman, J., Kees, J., \& Sprott, D. (2010). Concern with immediate consequences magnifies the impact of compulsive buying tendencies on college students' credit card debt. The Journal of Consumer Affairs, 44(1), 155-178.

Kellett, S., \& Bolton, J. V. (2009). Compulsive buying: A cognitive-behavioural model. Clinical Psychology and Psychotherapy, 16, 83-99. doi: 10.1002/cpp.585

Koran, L. M., Bullock, K. D., Hartston, H. J., Heidi, J., Elliott, M. A., \& D'Andrea, V. (2002). Citalopram treatment of compulsive shopping: An open-label study. Journal of Clinical Psychiatry, 63, 704-708. doi: 10.4088/JCP.v63n0808

Koran, L. M., Faber, R. J., Aboujaoude, E., Large, M. D., \& Serpe, R. T. (2006). Estimated prevalence of compulsive buying behavior in the United States. American Journal of Psychiatry, 163(10), 1806-1812.

Lynam, D. R., Smith, G. T., Whiteside, S. P., \& Cyders, M. A. (2006). The UPPS-P: Assessing five personality pathways to impulsive behavior. Technical Report. Purdue University. West Lafayette. Retrieved from http://www1.psych.purdue.edu/ dlynam/uppspage.htm

McElroy, S. L., Keck, P. E., Pope, H. G., Smith, J. M., \& Strakowski, S. M. (1994). Compulsive buying: A report of 20 cases. Journal of Clinical Psychiatry, 55(6), 242-248.

Miltenberger, R. G. R. G., Redlin, J. J., Crosby, R. R., Stickney, M. M., Mitchell, J. J., Wonderlich, S. S., ... Smyth, J. J. (2003). Direct and retrospective assessment of factors contributing to compulsive buying. Journal of behavior therapy and experimental psychiatry, 34(1), 1-9. 
Mitchell, J. E., Burgard, M., Faber, R., Crosby, R. D., \& de Zwaan, M. (2006). Cognitive behavioral therapy for compulsive buying disorder. Behaviour Research and Therapy, 44(12), 1859-1865. doi: 10.1016/j.brat.2005.12.009

Mowen, J. C., \& Spears, N. (1999). Understanding compulsive buying among college students: A hierarchical approach. Journal of Consumer Psychology, 8(4), 407-430. doi: 10.1207/s15327663jcp0804_03

Mueller, A., Claes, L., Mitchell, J., Wonderlich, S., Crosby, R., \& De Zwaan, M. (2010). Personality prototypes in individuals with compulsive buying based on the Big Five Model. Behaviour Research and Therapy, 48, 930-935. doi: 10.1016/j.brat.2010.05.020

Mueller, A., Mitchell, J., Crosby, R., Cao, L., Johnson, J., Claes, L., \& de Zwaan, M. (2012). Mood states preceding and following compulsive buying episodes: An ecological momentary assessment study. Psychiatry Research(In Press). doi: 10.1016/j.psychres.2012.04.015

Mueller, A., Mueller, U., Silbermann, A., Reinecker, H., Bleich, S., \& Mitchell, J. E. (2008). A randomized, controlled trial of group cognitive behavioural therapy for compulsive buying disorder: posttreatment and 6-month follow-up results. Journal of Clinical Psychiatry, 67, 1131-1138.

Parrotta, J. L., \& Johnson, P. J. (1998). The impact of financial attitudes and knowledge on financial management and satisfaction of recently married individuals. Financial Counseling and Planning, 9(2), 60-75.

Pham, T. H., Yap, K., \& Dowling, N. A. (2012). The impact of financial management practices and financial attitudes on the relationship between materialism and compulsive buying. Journal of Economic Psychology, 33(3), 461-470. doi: doi:10.1016/j.joep.2011.12.007 
Preacher, K. J., \& Hayes, A. F. (2008). Asymptotic and resampling strategies for assessing and comparing indirect effects in multiple mediator models. Behavior Research Methods, 40(3), 879-891. doi: 10.1037/0021-843x.112.4.558

Rose, P. (2007). Mediators of the association between narcissism and compulsive buying: The roles of materialism and impulse control. Psychology of Addictive Behavior, 21(4), 576581. doi: 10.1037/0893-164X.21.4.576

Whiteside, S. P., \& Lynam, D. R. (2001). The Five Factor Model and impulsivity: Using a structural model of personality to understand impulsivity. Personality and Individual Differences, 30, 669-689.

Williams, A.D. (2012a). Evaluation of the mood repair hypothesis of compulsive buying. Open Journal of Psychiatry, 2, 83-90. doi: 10.4236/ojpsych.2012.22012

Williams, A. D. (2012b). Are compulsive buyers more impulsive? Evidence of poor responseinhibition and delay discounting. Journal of Experimental Psychopathology, 3, 794-806. doi: $10.5127 /$ jep.025211

Williams, A. D., \& Grisham, J. R. (2011). Impulsivity, emotion regulation, and mindful attentional focus in compulsive buying. Cognitive Therapy and Research. doi: $10.1007 / \mathrm{s} 10608-011-9384-9$

Witkiewitz, K., \& Bowen, S. (2010). Depression, craving, and substance use following a randomized trial of mindfulness-based relapse prevention. Journal of Consulting and Clinical Psychology, 78, 362-374. doi: 10.1037/a0019172 
Table 1.

Demographic details of the sample $(N=162)$

$\begin{array}{lll}\text { Demographic } & n & \%\end{array}$

Education

High school or less

28

17.3

Currently in University

$18 \quad 11.1$

University degree

116

71.6

Employment status

Part-time employment ( $<40$ hours)

54

33.3

Full-time employment ( $\geq$ 40hours)

43.2

Unemployed

70

23.5

Personal income

$<\$ 50,000$

86

53.1

$\$ 50,000$ - $\$ 100,000$

57

35.2

$\geq \$ 100,000$

19

11.7

Household income

$<\$ 50,000$

31

19.1

$\$ 50,000$ - $\$ 100,000$

62

38.3

$\geq \$ 100,000$

69

42.6

Number of Credit Cards

$\begin{array}{lll}0 & 34 & 21.0 \\ 1 & 75 & 46.3 \\ \geq 2 & 53 & 32.7\end{array}$

Debt (not including mortgage)

$<\$ 5,000$

108

66.7

$\$ 5,000-\$ 20,000$

23

14.2

$\geq \$ 20,000$

31

19.1

Note. All currency in Australian dollars. 
Table 2

Means (including 95\% Confidence Intervals), Standard Deviations, and Spearman's

Correlations among CBS, DASS-Total, NUI, and FMS ( $n=162)$

\begin{tabular}{|c|c|c|c|c|c|}
\hline Variables & $M(S D)$ & $95 \% \mathrm{CI}$ & CBS & DASS-T & NUI \\
\hline CBS & $1.16(1.62)$ & {$[0.91,1.41]$} & & & \\
\hline DASS-Total & $27.40(22.13)$ & {$[23.96,30.83]$} & $-.30 *$ & & \\
\hline NUI & $2.28(0.57)$ & {$[2.19,2.37]$} & $-.31 *$ & $.44^{*}$ & \\
\hline FMS & $111.39(26.36)$ & {$[107.30,115.48]$} & $.40 *$ & $-.27 *$ & $-.33 *$ \\
\hline \multicolumn{6}{|c|}{ Note. CBS = Compulsive Buying Scale; DASS-Total = Depression Anxiety Stress Scale Total; } \\
\hline \multicolumn{6}{|c|}{ NUI= UPPS-P Negative Urgency Impulsivity Subscale; FMS = Financial Management Practices } \\
\hline \multicolumn{6}{|c|}{ Scale; $\mathrm{CI}=$ Confidence Interval. } \\
\hline
\end{tabular}




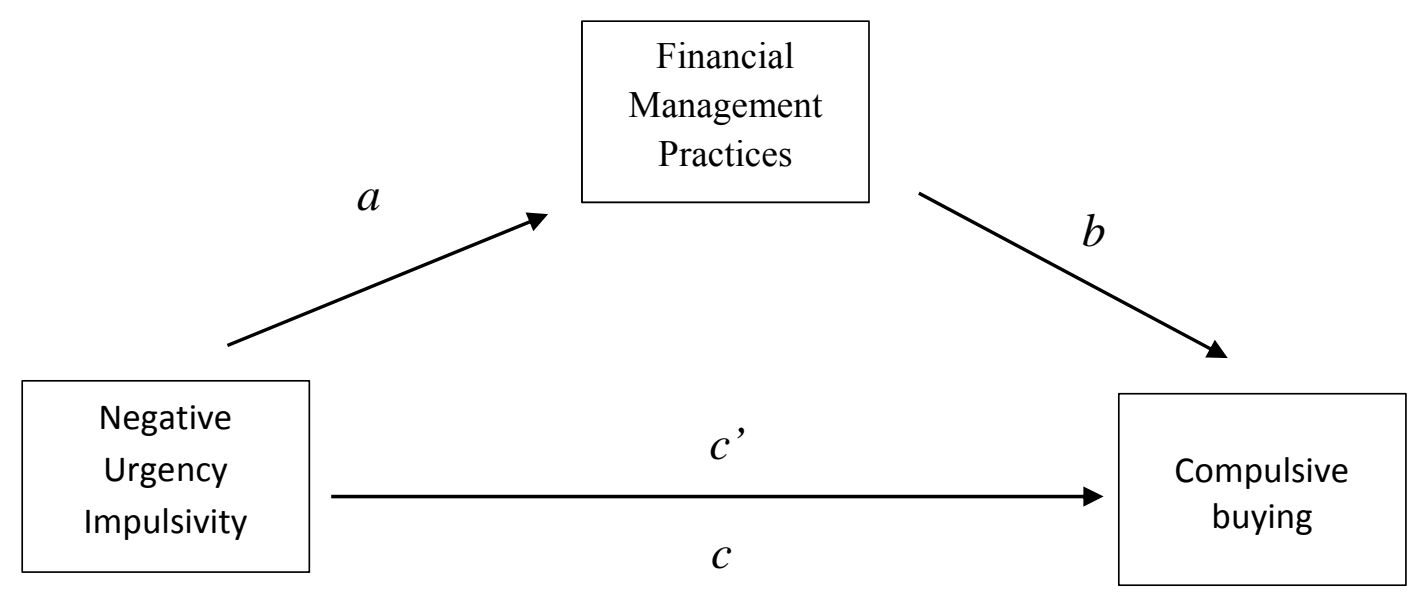

Figure 1. Proposed mediation model. Negative urgency impulsivity exerts effects on the mediating variable (financial management practices) ( $a$ path), which in turn influences the compulsive buying ( $b$ path). Negative urgency impulsivity has a direct effect on compulsive buying, when controlling the mediator ( $c^{\prime}$ path). The total effect of negative urgency impulsivity on compulsive buying is the $c$ path. 